(C) Copyright 2020: Editum. Servicio de Publicaciones de la Universidad de Murcia. Murcia (Spain) ISSN print edition: 0212-9728. ISSN online edition (http://revistas.um.es/analesps): 1695-2294.

Online edition License Creative Commons 4.0: BY-SA

\title{
Development and Validation of the Spanish Version of the Political Skill Inventory: A Measurement Invariance Test
}

\author{
Rebeca Cepas González, Paula Ruiz-Zorrilla Blanco, Francisco Gil Rodríguez, and Mirko Antino*
}

Universidad Complutense de Madrid (Spain).

Título: Desarrollo y validación de la versión española del Inventario de Habilidades Políticas: una prueba de invarianz de medición.

Resumen: Introducción: El inventario de habilidades políticas (PSI, siglas en inglés) es una medida para calibrar cuatro dimensiones relacionadas con este constructo: la astucia social, la capacidad de influencia interpersonal, la habilidad para establecer contactos y la sinceridad aparente (Ferris, Davidson \& Perrewé, 2005)

Método: En el presente estudio, multi-muestra y multi-método, sendos análisis factorial exploratorio y confirmatorio se han llevado a cabo sobre dos muestras, una primera compuesta por trabajadores de varios ramos (recogido en tres etapas, con una edad media comprendida entre 43.66 y 44.70 años, $D T=9.42-10.22$, y un porcentaje de mujeres entre $57.3-58.4 \%$ ) y una segunda por trabajadores del sector salud $\left(M_{\text {age }}=35.56, S D=7.23\right.$; $80.6 \%$ women), para desarrollar y testar las propiedades psicométricas de la versión española del PSI. Adicionalmente, se llevó a cabo una prueba de fiabilidad longitudinal y un análisis de invarianza relativo al género.

Resultados: Los índices alpha de Cronbach (cuyos valores oscilaron entre 0.83-0.90 en nuestros datos, y entre $0.73-0.87$ en la versión original) y omega (0.85 para el total de la escala) revelaron un grado de fiabilidad satisfactoria. El análisis factorial exploratorio extrajo los cuatro factores de la versión original, tal y como ya ha sido reportado en otros estudios $(\mathrm{N}=309)$. $\mathrm{El}$ análisis factorial confirmatorio confirmó que el ajuste de dicha estructura fue el mejor frente a los datos $(\mathrm{N}=248)$.

Conclusiones: Con este estudio se añade evidencia al estudio de la invarianza de género y la estabilidad temporal de esta medida, mostrando que la versión española del PSI puede ser considerada una medida estable y válida a través del tiempo y relativa al género.

Palabras clave: Habilidades del empleado; Psicología Organizacional; Validez de constructo; Estructura factorial; Análisis multigrupo.

\section{Introducción}

While organizational contexts are substantively becoming more complex, the emphasis on discovering key individual factors can be helpful to disentangle these interconnected environments. In this light, organizations are networks that can be seen from different perspectives. Addressing one of those points of view, organizations can be considered political niches (Minztberg, 1985). As Pfeffer explained (1991), "organizational politics involve the activities that are taken within organizations to acquire, develop and use power and other resources to obtain the preferred results in a situation in which there is uncertainty or dissent over options" (p.7). Given this context, for example, leaders' abilities to navigate these environments turn to be key factors for both global and individual success (Ferris, et al., 2007).

\section{* Correspondence address [Dirección para correspondencia]:}

Mirko Antino, Prof. Dpto. Psicobiología y Metodología de las Ciencias del Comportamiento Facultad de Psicología, Despacho 2104.D. Universidad Complutense de Madrid, Campus de Somosaguas, 28223 Madrid (Spain).

E-mail: m.antino@psi.ucm.es

(Article received: 17-3-2019, revised: 22-7-2019, accepted: 5-11-2019)
Abstract: Background: The Political Skills Inventory (PSI) is a measurement tool for assessing four dimensions associated with political skills: social astuteness, interpersonal influence, networking ability and apparent sincerity (Ferris, Davidson \& Perrewé, 2005).

Method: In the present study, multi-sample and multi-method, we developed and analyzed the psychometric properties of the Spanish version of the (PSI), by performing both exploratory and confirmatory factor analyses over two samples composed by employees from diverse professions for the first sample (collected through three waves, with values ranging between $M_{\text {age }}=43.66-44.70, S D=9.42-10.22$ and $57.3-58.4 \%$ of women) and a healthcare workforce for the second one $\left(M_{\text {age }}=35.56, S D=\right.$ 7.23 ; $80.6 \%$ women). Additionally, a longitudinal reliability test and a gender factorial invariance test were performed.

Results: Cronbach's alpha (ranging between 0.83-0.90 in our data and between $0.73-0.87$ in the original version) and omega ( 0.85 for the overal scale) indices revealed satisfactory reliability and exploratory factor analyses extracted the four original factors as reported in other studies $(\mathrm{N}=309)$. Confirmatory factorial analyses confirmed that the four-factor solution presented the best fit to our data $(\mathrm{N}=248)$.

Conclusions: We add new evidence for time and gender invariance of the measure, showing that the PSI can be considered a stable and valid measure over time and across gender.

Keywords: Employee Skills; Political Skill; Organizational Psychology; Construct Validity; Factorial Structure; Multiple-group Analysis.

In this sense, abilities are understood as skills and competences, as they represent specific desirable qualities for employment. Although skills and competencies seem to be synonym concepts, they are two different elements within the learning process (Chryssolouris, Mavrikios \& Mourtzis, 2013). While "competencies" are formal capabilities (which can be cognitive, emotional, communicative, social, perceptual or personality factors) that underlie the possibility of mastering a given situation (Ellstrom \& Kock, 2009); "skills" are applied abilities (what is commonly known as "know how"), as they allow individuals to have general cognitive and practical dexterities (Bloom, Engelhart, Furst, Hill \& Krathwohl, 1956). Coherently, skills function as the bricks to build any specific situated knowledge about procedures and contexts. For example, one can have a good memory and be skilled on task switching (skills), and these components may help him/her to master the decision-making processes (competency) on a sales company. Due to the fact that political skill is formed by other personal traits related to social abilities (e.g. social and emotional intelligence, ego-resiliency, social self-efficacy, self-monitoring or tacit knowledge; Ferris, Perrewé, Anthony \& Gilmore, 2003), it is expected to 
behave on a more temporal stable basis, and thus, to be an ability which is sustained over time.

Furthermore, performance and effectiveness in organizations depend also on workforce's individual differences, such as intelligence, training, dedication and effort (Luthans, Hodgetts \& Rosenkrantz, 1988). Within this literature and during the last decade, a growing interest has been dedicated to a particular key individual difference variable for understanding people's behavior at work: political skill (PS; Blickle et al., 2011a), defined as needed skills to successfully influence through persuasion, manipulation, and negotiation. Since it was proposed, PS have been linked to different social phenomena. At the beginning, some authors considered that it was mainly related to power, both formal (Minzberg, 1983) and informal (Perrewé et. al., 2004). Later, additional studies have linked PS with interpersonal communicative styles and social competencies (Ferris et. al., 2007; Zellars et. al., 2008). People with high PS are considered flexible, with great capacity for adaptation and effective in personal relationships (Momm, Blickle \& Liu, 2017; Liu, et al., 2007). Additionally, PS have also been shown to be positively related to performance (Ahearn, Ferris, Hochwarter, Douglas \& Ammeter, 2004; Moss \& Barbuto, 2010) and other outcomes of the organization (Ferris et al, 2005a; 2008), such as work stress management and work satisfaction (Kolodinsky, Hochwarter, \& Ferris, 2004). Specifically, political skill has been raised as a fundamental ability to cope with strain and buffer leaders' stress, by allowing individuals to gain control on interpersonal interaction and to differently interpret everyday work stressors (Perrewé, Ferris, Frink \& Anthony, 2000).

In addition, it has been shown that political skill is positively related to the success of initiation into innovation (Grosser, 2014). In particular, the beginning of a successful innovation may act as a mediator between political skill and professional success (Block, 2016). People with political skill not only gain themselves, as mentioned above, but tend to produce benefits on others, in their groups as well as their organizations (Ferris, 2008). What's more, people with political skill tend to prioritize and respond appropriately to the information obtained, by reducing role ambiguity (Cullen, Gerbasi \& Chrobot-Mason 2018).

Regarding differences depending on sociocultural and demographic factors, some authors have delivered contradictory results concerning gender differences. Already during the nineties DuBrin asserted that that gender roles often involve the use of different influence tactics (DuBrin, 1990). Focusing on political skill, some discussion relative to gender differences has taken place during the last decades, arising not always homogeneous results. In this sense, while Ferris, Davidson and Perrewé (2005) stated that women were less likely to use political skill at the workplace, Shaughnessy and colleagues (2010) asserted that behavioral expectations based on gender-roles may alter the effectiveness of influence behaviors over subordinates' ratings of liking. That is, those behaviors that were contrary to gender-role expectations were less effective that those which were not. In this line, women with political skill had the potential of making leaders more able to perceive, interpret and adapt their behavior to diverse social settings, and thus, exert more influence over their workers. What is more, Phipps and Prieto (2015) explored gender differences on entrepreneurship intentions, creativity and political skill, and found that while men were more likely to have entrepreneurship intentions and creativity perceptions, women were more likely to cause political skill perceptions than men. However, on its recent review, Kimura (2015) argues that in addition to the fact that women are probably less likely to display political skill due to congruent gender-based behavior, as they acquire larger experience on organizational politics, they become more likely to recognize the need of political-oriented behavior (Doldor, Anderson \& Vinnicombe, 2013; Mainiero 1994). In congruence with this statement, Ajayi (2018) argued that women in global leadership positions are frequently in more need of demonstrating political skill to achieve their positions (on their discourses about their professional careers, they use to highlight topics such as resilience, fearless and consistency). This has been also noticed among African American women (Stone, 2018). Even more, the display of political skill may be beneficial for women. Some authors (Treadway, Campion \& Williams, 2017) pointed out to the usefulness of political skill to buffer powerless minorities (like women in organizations) psychological and physical consequences. In fact, they found that political skill was moderating the effect of powerless perceptions over anxiety, strain, depression, somatic complaints, illness and memory loss, being those individuals higher on political skill those who presented fewer negative symptoms.

On the other hand, with regard to cultural differences, evidence has shown that political skill can be treated as a stable construct among various cultural groups, including China, Germany, Russia, Turkey, and the United States, where it can be concluded that political skills are also useful for expatriates' competencies for adjustment and professional success outside their country (Lvina, et al., 2012). Nevertheless, to date, there is still no adaptation of the measure to the Spanish population.

Concerning its conceptual distinctiveness and measurement, political skill is commonly measured through the Political Skill Inventory (Ferris et. al., 2005), which serves to clearly differentiate the construct from others, like "emotional intelligence", "social intelligence", "self-efficacy" or "self-monitoring" (Kimura, 2015). As the authors comment, even if all those behaviors pertain to the family of social effectiveness abilities, political skill have particular properties, such as being a work-specific behavior, having a combination between knowledge and skill, being less general and closer to work-outcomes, or having the purpose of promoting change rather than just perform adaptative social behaviors. 


\section{The Political Skill Inventory (PSI)}

To properly measure PS, Ferris et al. (2005), developed the Political Skill Inventory (PSI), in order to capture "the ability to effectively understand others at work, and to use such knowledge to influence others to act in ways that enhance one's personal and/or organizational objectives" (Ahearn, et al., 2004, p. 311).

The authors developed the PSI as a 40-item version reflecting four dimensions (Ferris, 1999), which was later shortened to an 18-item version and tested over a sample of US samples (Ferris, et al., 2005). The measure was developed along three studies, involving 7 samples (two for the first study, composed by 220 workers and 226 undergraduate students, three samples for the second study, composed by 203 and 148 full-time and long-term workers, and 184 undergraduate students, and two for the third study, who were 35 school administrators and 474 branch managers). The first study developed the measure and analyzed its dimensionality. The second study was performed to replicate (confirm) the factorial structure and thus, to dig deeper into convergent and discriminant validity evidences. Finally, the third study assessed criterion validity by implementing the measure on two samples composed by managerial positions. In sum, the initial scale showed internal consistency (Cronbach alpha) ratings between 0.86 and 0.90 for the overall measure, and $0.58-0.87$ for its subscales.

Despite the previous 40-item complete version (Ferris et. al., 1999), for this study we took the PSI short version, which is composed by 18 items. The main reason for this choice is that it is the most common used in the literature (Jawahar, Stone and Kisamore, 2007; Lvina, et al., 2012).

The four dimensions of PSI tackle the following aspects:

1- Social astuteness. It is related to interpersonal influence, networking ability and apparent sincerity. Based on the original definition, "are astute observers of others and are very interested in various social situations" (Ferris et. al., 2005, p. 129). This scale is composed of five items, with an alpha value of 0.79 (Ferris et. al., 2005) An example is: "I understand people very well".

2- Interpersonal influence. According to the original definition, "individuals with a high level of interpersonal influence are capable of adequately adaptability" (Ferris et. al., 2005 ; 129). It is composed by four items, with alpha values between 0.77-0.78 (Ferris, 2005). An example of item for this subscale is "I am able to make most people feel comfortable and at ease around me".

3- Networking ability. Based on the original definition, it relates to the tendency of considering "that assets are valuable and necessary for the success of personal and organizational functioning" (Ferris et. al., 2005; p.129). They found six items associated to it, with alpha values ranging from 0.82 to 0.87 (Ferris et. al., 2005). An example is "I spend a lot of time and effort at work networking with others".
4- Apparent sincerity. Based on the original definition, it means "possessing high levels of integrity, authenticity, sincerity and authenticity". (Ferris et. al., 2005; 129). This scale is composed of three items, with alpha values ranging from 0.73 to 0.84 (Ferris et. al., 2005). An example is: "It is important for people to believe that I am sincere in what I say and do."

The Political Skills Inventory (PSI) has shown to be consistent in different cultures, like China, Germany, Russia, Turkey, and the United States. Despite the wide use of the scale and the big effort to properly test the metric qualities of the instrument, there are still some research questions that remain unsolved. First, to the best of our knowledge, until now time stability has not been explored for this construct. Second, there is no empirical evidence about potential gender differences on the construct, a key factor within the individual differences' literature (Cinamon \& Rich, 2002). Third, the psychometric tests rarely include the study of the relationship between the PSI and other external variables (for an exception see Coole, 2006; Ferris et al. 2005). Fourth, despite the wide use of Spanish language, until the date there is no validation of the scale available.

Given the specificity and potential of the construct in connection with many work-related dynamics, we aim to adapt and validate this instrument to the Spanish population, as well as to contribute to test its temporal stability, gain more insights about gender differences and to add more evidence about its relation with other key work-related behaviors, like innovative work behavior (IWB; Farr \& Ford, 1990).

\section{The present study}

Our study aims to cover the previously mentioned gaps. First, we developed a Spanish version of the PSI and test its psychometric properties performing several exploratory and confirmatory factor analyses on two separate samples, thus studying the fit of the theoretical four factor structure. Second, we studied the stability of the PSI over time with our first sample (where participants were measured three times) performing a retest reliability test. Third, we evaluated the factorial invariance related to gender, to study the level of equivalence of measurement between groups. Our fourth and final objective was to provide evidence of criterion validity with external variables, so we related PSI measured in Time 1 with innovative work behaviors, a key organizational outcome (Janssen, 2000). Finally, theoretical and practical implications are discussed. 


\section{Method}

\section{Participants and procedure}

\section{Samples}

We collected data by reaching two different samples. The first sample has been collected through a longitudinal research design, with 3 waves of data collection, with 2 months of delay between each measurement. The participants were collected with a convenience sampling, recruiting voluntary participants through researchers' and students' social networks (professional and common social network), asking each participant to further share our research among their contacts (snowball). The contacted participants who agreed signed a confidentiality document where the finality of the research was explained and were the anonymity of the data collection was guaranteed (informed consent). After, they answered a single self-rated questionnaire comprising two measures (PSI and IWB). Among the final sample of interested participants, the first wave included 309 workers in the first wave of data collection, coming from a large variety of working sectors including general service sector (the prevalent sector with around $60 \%$ of the participants), energy, construction, manufacturing, etc. With regard to the demographic characteristics $57.3 \%$ were women, age: $M=43.66$, $S D=10.22$; response rate of $78,1 \%$. The second wave included 248 participants (response rate $=69 \%, 57,9 \%$ were women, age: $M=44.70, S D=9.42)$, and the third wave included 188 (response rate $=61 \%, 58,4 \%$ were women, age: $M=44.37, S D=10.14)$. We collected the data through an online survey platform. Our second sample came from a Spanish healthcare company and was composed by 248 respondents (age: $M=35.56, S D=7.23 ; 80.6 \%$ were women). The healthcare Company was approached during a collaboration in a broader research project with one of the coauthors. The research has been presented to and approved by the ethical committee of the research and development department of the company, that took charge of sharing the link to the electronic survey platform to facilitate the participation. Participation was voluntary and anonymity of the responses was guaranteed.

\section{Measures}

Political Skill Inventory (PSI) - is composed by 18 items giving account for 4 theoretical dimensions, namely social astuteness, interpersonal influence, networking ability and apparent sincerity. The Spanish version has been obtained following a multistep procedure. In the first step, two expert psychologists translated the English version of the PSI into Spanish separately into Spanish. In the second step, they compared their translation and agreed on a common version (minor formal differences were found). In third step, they discussed the agreed version with a third researcher in an organizational psychology field. In the fourth step, an English native speaker (expert on organizational psychology) back translated it on a item-by-item basis; finally, in the fifth step two experts (one of them external to this research, 2 associate professors) compared the translated versions with the original one and found no substantial differences. Therefore, the we maintained the translated version. The items were presented with a Likert scale of 7 points $(0=$ totally disagree, $6=$ totally agree).

Innovative work behavior (IWB) - has been measured using 9 items (Janssen, 2000) with a Likert scale of 7 points $(0=$ totally disagree, $\sigma=$ totally agree). $\sigma=0.9$

\section{Analytical procedure}

According to our goals, the psychometric analysis of the Spanish version of the PSI will apply: a) internal consistency tests, b) exploratory factorial analysis (on the first sample) to study the theoretical structure of the PSI, c) confirmatory factorial analysis (CFA) to test the robustness of the four factors solution, d) test-retest reliability, to study the time stability of the construct, e) metric invariance test for gender, and $\mathrm{f}$ ) criterion validity to study the relationship between PSI and IWB.

\section{Results}

\section{Reliability and Item Analysis}

Reliability and item analysis calculated over the 557 respondents were acceptable. Cronbach's alpha coefficient for assessing the internal consistency of Political Skill inventory was 0.896 for the overall scale and ranged between $0.83-0.90$ for the subscales. Additionally, the internal consistency analysis was complemented with the estimation of the omega coefficient (Dunn, Baguley \& Brunsden, 2014), with a result of 0.85 for the overall scale. Correlations item-test were also acceptable within the range of 0.114-0.669.

\section{Exploratory factor analysis}

Before conducting our analyses, we both test for: a) indicators of normality, with Mardia $(p<0.01)$ and KolmogorovSminrov $(\mathrm{p}<0.01)$ tests, which together indicated a slight violation of normality (reason why we choose the ULS method and not the ML); and b) the appropriateness of our data for conducting an exploratory factor analysis (EFA). The Kaiser-Meyer-Olkin measure of sample adequacy was 0.913 (Cerny, \& Kaiser, 1977), and the Bartlett sphericity test was significant $(\mathrm{p}<0.001)$, thus indicating the suitability of our sample for the subsequent analyses.

Then, the EFA was performed using the ULS estimator (because of the reason mentioned above) and oblimin rotation (Finney \& DiStefano, 2006). Parallel analysis suggested the retention of 4 factors, accounting for the $62.76 \%$ of variance, where only one item presented a factorial loading lower than 0.3 with its theoretical factor. 
Table 1. EFA of 4 Factors vs. 1 factor using the ULS method.

\begin{tabular}{|c|c|c|c|c|c|}
\hline & \multicolumn{4}{|c|}{4 Factors } & \multirow[t]{2}{*}{1 Factors } \\
\hline & II & SA & $\mathrm{NA}$ & AS & \\
\hline V1 & & & 0.316 & & 0.179 \\
\hline V2 & 0.695 & & 0.113 & & 0.623 \\
\hline V3 & 0.792 & & & & 0.632 \\
\hline V4 & 0.799 & & & & 0.598 \\
\hline V5 & 0.106 & 0.551 & 0.132 & & 0.577 \\
\hline V6 & 0.497 & 0.440 & & & 0.714 \\
\hline V7 & 0.251 & 0.401 & 0.315 & & 0.751 \\
\hline V8 & 0.164 & 0.639 & & & 0.707 \\
\hline V9 & 0.209 & 0.124 & -0.143 & 0.476 & 0.490 \\
\hline V10 & & & 0.722 & & 0.611 \\
\hline V11 & & & 0.824 & & 0.620 \\
\hline V12 & 0.339 & 0.124 & 0.361 & & 0.675 \\
\hline V13 & 0.232 & & & 0.608 & 0.533 \\
\hline V14 & & 0.139 & 0.572 & 0.150 & 0.668 \\
\hline V15 & & 0.103 & 0.160 & 0.590 & 0.552 \\
\hline V16 & & 0.635 & & 0.197 & 0.734 \\
\hline V17 & -0.177 & 0.493 & 0.222 & 0.167 & 0.619 \\
\hline V18 & & 0.367 & & 0.125 & 0.472 \\
\hline
\end{tabular}

\section{Confirmatory factor analysis}

Confirmatory factor analysis was performed in sample 2, using a robust variant of the Maximum Likelihood extraction method (MLM; Finney \& DiStefano, 2006). To reach an appropriate fit, we eliminated item 5 from the pool (which also showed unacceptable levels of cross loading), finding finally an acceptable fit to our data: the 4 correlated factors model $\left(\chi^{2} / d f=3.791, \mathrm{CFI}=0.91, \mathrm{RMSEA}=0.08\right)$, followed by the second-order model, $\left(\chi^{2} / d f=3,861, \mathrm{CFI}=0.87\right.$, RMSEA $=0.10)$.

Table 2. Comparison of CFA models. First order model vs. Second order model.

\begin{tabular}{lccc}
\hline Model & $\chi^{2} / \mathrm{df}$ & CFI & RMSEA \\
\hline $1^{\circ}$ order & 3.791 & 0.91 & 0.08 \\
$2^{\circ}$ order & 3.861 & 0.87 & 0.10 \\
\hline
\end{tabular}

\section{Internal consistency and Test-retest reliability}

We estimated reliability for the PSI whole scale and the theoretical dimensions using the whole sample (sample 1, time 1, and sample 2); as shown in tables 3 and 4, we obtained satisfactory values. Using Sample 1, we explored the test-retest reliability of the PSI by correlating all the dimensions across three waves using the longitudinal survey sample. Results showed that networking ability measured at Time 1 was positively and significantly related to its measurement at Time $2(r=.66, p<.01)$ and Time $3(r=.58$, $p<.01$ ), and the relationship between Time 2 and Time 3 was $r=.69, p<.01$. Interpersonal influence measured at Time 1 was positively and significantly related to its measurement at Time $2(r=.64, p<.01)$ and Time $3(r=.61, p<.01)$, and the relationship between Time 2 and Time 3 was $r=.66, p<.01$. Social astuteness at Time 1 was positively and significantly related to its measurement at Time $2(r=.60, p<.01)$ and Time $3(r=.68, p<.01)$, and the relationship between Time 2 and Time 3 was $r=.59, p<.01$. Finally, apparent sincerity measured at Time 1 was positively and significantly related to its measurement at Time $2(r=.63, p<.01)$ and Time $3(r=.64$, $p<.01)$, and the relationship between Time 2 and Time 3 was $r=.56, p<.01$. In summary, all the test-retest correlation values were positive and with moderate strength (Ferguson, 2009), ranging from 0.56 to 0.69 , exceeding the minimum correlation of .40 to establish the stability of the measure.

Table 3. Longitudinal values of Cronbach's alfa for Sample 1.

\begin{tabular}{lc}
\hline Times & Cronbach`s alfa \\
\hline Time 1 & 0.913 \\
Time 2 & 0.881 \\
Time 3 & 0.880 \\
\hline
\end{tabular}

\section{Gender Invariance Test}

We assessed measurement invariance through a cross sample comparison (woman and men of both samples) and found that in our sample we had no significantly different factor number $(\Delta \chi 2=7.898, \Delta d f=14, p=n s)$, supporting configural invariance. Secondly, we found metric invariance, which means that in our two samples we had no significantly different (unstandardized) factor loadings $\left(\Delta \chi^{2}=35.371, \Delta \mathrm{df}\right.$ $=28, p=\mathrm{ns}$ ). Then, we tested the between-group equality of indicator intercepts, but we found that the means of the indicators were different between our samples.

\section{Evidence for Validity based on prediction of other variables}

To offer additional evidence for validity based on the prediction of other variables, using a time lagged approach, we studied how PS in time 1 predicted IWB in time 3 - As shown in Table 4 , the PSI (at time 1) was positively related to the innovative behavior of the work $(r=.32, p<.00)$, and all of its scales also (ranging from $r=.23, p<.00$ and $.29, p$ $<.00)$. Specifically, the dimensions social astuteness and apparent sincerity, demonstrated a higher correlation $(.29, p<$ .00 and $.29, p<.00)$.

Table 4. Bivariate correlations between PSI and IWB.

\begin{tabular}{|c|c|c|c|c|c|c|c|}
\hline & Reliability & 1 & 2 & 3 & 4 & 5 & 6 \\
\hline 1. Innovate Work Behavior T3 & $\sigma=.90$ & 1 & & & & & \\
\hline 2. Political Skill Inventory T1 & $\sigma=.89$ & $0.32 * *$ & 1 & & & & \\
\hline 3. Networking Ability T1 & $\sigma=.83$ & $0.23^{* *}$ & $0.84^{* *}$ & 1 & & & \\
\hline 4. Interpersonal Influence T1 & $\sigma=.86$ & $0.26 * *$ & $0.85^{* *}$ & $0.57^{* *}$ & 1 & & \\
\hline 5. Social Astuteness T1 & $\sigma=.85$ & $0.29 * *$ & $0.88^{* *}$ & $0.63^{* *}$ & $0.68^{* *}$ & 1 & \\
\hline 6. Apparent Sincerity T1 & $\sigma=.84$ & $0.29 * *$ & $0.71 * *$ & $0.49 * *$ & $0.54 * *$ & $0.54^{* *}$ & 1 \\
\hline
\end{tabular}
$* * p<.01$ 


\section{Discussion}

Our first aim was to adapt and explore the psychometric properties of the Spanish version of the Political Skill Inventory (PSI), which extends the previous evidence in the literature about political skills measurement. Psychometric tests with the 18-items reduced version showed good results. That is, the structure of the original scale was replicated (except for item 5), with an acceptable proportion of variance explained, which was above the recommended value of $60 \%$ (Hair, Black, Babin \& Anderson, 2014). All the 17 final items presented loadings above 0.3 (Hair et. al., 2014) The internal consistency test and the reliability estimation delivered acceptable results, being in all case above 0.80 (including all three time-point measurements). The CFA suggested that the correlated four-factors models exhibited an acceptable fit to our data (with the deletion of item 5, for which we found a problematic cross loading between factors interpersonal influence and social astuteness).

According to our second aim, the test retest correlation values were positive and significant (with values comprised between 0.56 and 0.69 in all cases). These results indicate that the instrument is stable over time. Thus, going back to the previous theorization about political skill as an ability which is formed by stable personal traits, this may serve to test those assumptions through longitudinal research.

In view of the scarce and heterogeneous results of gender differences (Ajayi, 2018; Ferris et. al., 2005; Kimura, 2015; Phipps \& Prieto, 2015; Shaughnessy et. al., 2010; Stone, 2018), our third aim was to evaluate the gender measurement invariance. Despite the statement of Ferris and colleagues (2005), for whom women were less likely to display political skills in a workplace context, and following Brown (2014), we found a second level of measure invariance (metric invariance). This means that the factor loading structure does not meaningfully vary between men and women, and thus, that we can attribute the same meaning of the construct to both genders. To our knowledge, this is the first evidence for gender measurement invariance in the PSI literature, while previous literature just showed a weak cultural invariance (Lvina et.al., 2012). Nevertheless, some gender differences can be found concerning the stability of the items across administrations (strong invariance) and related to the equality of factor variances and residuals (or strict factorial invariance; Putnick \& Bornstein, 2016).

Our fourth objective was to find criterion validity by correlating the PSI scales with the IWB. According to our results, PS can be considered as an antecedent of IWB, in line with previous indications in the literature (Janssen, 2000; DeJong \& Den Hartog, 2008). As those authors pointed out, participative leadership is a key factor on employees' innovative behaviors at work through fostering collective decisionmaking processes and enhancing its motivation. In this sense, our result shows how specific leader-related behavior may be an antecedent of innovation (DeJong \& Den Hartog, 2008).

\section{Practical implications}

Concerning practical implications, political skill seems to be a key feature for success and performance in organizations within several work contexts (Ferris, et al., 2005). Until now, in Spain and Latin American countries the full version of the PSI has not been available. Therefore, the translation and psychometrical analysis of the PSI in its complete version has a lot of practical value. Through its application, professionals could provide evidence of change and development in existing work organizations, using evaluation as a guide for goal setting. In this line, our results add information to the PSI literature, where authors like Liu, et al., (2007), affirmed that more research on the psychometric properties of the PSI was needed in order to recommend the Political Skill Inventory for selection purposes.

\section{Conclusion}

To sum up, our goals were to assess the PSI psychometric properties in several ways (internal consistency, reliability, factorial structure, temporal stability, measurement invariance and criterion validity). The scale showed good reliability and internal consistency properties, and the CFA delivered a final 17-item Spanish version, preserving the PSI original factor structure. Concerning temporal stability, the measure appeared to be stable throughout all three measurements. Related to gender group invariance, the PSI showed a significant degree of weak invariance, which means the equality of factor loadings across gender groups. Finally, the assessment of criterion validity may indicate that PS is an antecedent of innovative work behaviors.

In conclusion, our work opens the possibility to use this measurement tool in Spanish speaking working contexts (for example, for selection purposes), adding new empirical evidence to the metric qualities of the scale.

\section{Limitations}

In addition to its theoretical and practical implications, our study is limited in several ways. Regarding the analysis of the criterion validity, we only analyzed the relationship of political skill with innovation. For this reason, future research should include more variables, such as those related to effective performance and job satisfaction (for which political skill could be a predictor). Second, although the Spanish version of the PSI seems to be a valid and reliable scale, future research should verify the existence of metric invariance in other Spanish-speaking cultures, to test whether the measuring instrument behaves in other countries. Third, we just focused on gender invariance, while future research could add new evidence on invariance related to other key variables, like potential contexts of application. Fourth, we also need to consider the difficulties and bias associated to the work with scales 
involving social networks (when participants ratings rely upon other's behaviors, or those behaviors which emerge in specific social circumstances), specially concerning the

\section{References}

Ahearn, K. K., Ferris, G. R., Hochwarter, W. A., Douglas, C. and Ammeter, A.P. (2004). Leader Political Skill and Team Performance. Journal of Management, 30(3), 309-327.

Ajayi, E. T. (2018). Exploring the Political Skills Required by Women to Become Global Political Leaders (Doctoral dissertation, Colorado Technical University).

Blickle, G., Kramer, J., Schneider, P.B., Meurs, J.A., Ferris, G.R., Mierke, J., Witzki, A.H., and Momm, T.D. (2011). Role of political skill in job performance prediction beyond general mental ability and personality in cross-sectional and predictive studies. Journal of Applied Social Psychology, 41, 239-265.

Block, P. (2016). The empowered manager: Positive political skills at work. New York: John Wiley \& Sons.

Bloom, B. S., Engelhart, M. D., Furst, E. J., Hill, W. H., \& Krathwohl, D. R. (1956). Taxonomy of educational objectives: the classification of educational goals. Handbook I: cognitive domain. New York: David McKay Company. Inc.(7th Edition 1972).

Brown, T. A. (2014). Confirmatory factor analysis for applied research. New York: Guilford Publications.

Cerny, C.A., and Kaiser, H.F. (1977). A study of a measure of sampling adequacy for factor-analytic correlation matrices. Multivariate Behavioral Research, 12, 43-47.

Chryssolouris, G., Mavrikios, D., \& Mourtzis, D. (2013). Manufacturing systems: skills \& competencies for the future. Procedia CIR $p, 7,17-24$

Cinamon, R. G., and Rich, Y. (2002) Gender Differences in the Importance of Work and Family Roles: Implications for Work-Family Conflict. Sex Roles, 47, pp 531-541.

Coole, D. R. (2006). Expansion and validation of the Political Skill Inventory (PSI): An examination of the link between charisma, political skill, and performance. Presented at the 21st Annual Conference of the Society for Industrial and Organizational Psychology, Dallas.

Cullen, K. L., Gerbasi, A., \& Chrobot-Mason, D. (2018). Thriving in central network positions: The role of political skill. Journal of Management, 44(2), 682-706.

De Jong, J. P., \& Den Hartog, D. N. (2008). Innovative work behavior: Measurement and validation. EIM Business and Policy Research, 8(1), 1-27.

Doldor, E., Anderson, D. and Vinnicombe, S. (2013). Refining the concept of political will: a gender perspective. British Journal of Management, 24, pp. $414-427$.

Douglas, C., \& Ammeter, A. P. (2004). An examination of leader political skill and its effect on ratings of leader effectiveness. The Leadership Quarterly, 15(4), 537-550.

DuBrin, A. J. (1990). Winning office politics: Dubrin's guide for the '90s. Paramus, NJ: Prentice-Hall, Inc.

Dunn, T. J., Baguley, T., \& Brunsden, V. (2014). From alpha to omega: A practical solution to the pervasive problem of internal consistency estimation. British journal of psychology, 105(3), 399-412.

Ellstrom P E \& Kock H. (2009). Competence development in the workplace: concepts, strategies and effects. In Illeris, K. (Ed.), International Perspectives on Competence Development. Developing Skills and Capabilities. London: Routledge.

Farr, J. L., \& Ford, C. M. 1990. Individual innovation. In M. A. West \& J. L. Farr (Eds.), Innovation and creativity at work: 63-80. Chichester, England: Wiley.

Ferguson, C. J. (2009). An effect size primer: a guide for clinicians and researchers. Professional Psychology: Research and Practice, 40(5), 532

Ferris, G. R., Berkson, H. M., Kaplan, D. M., Gilmore, D. C., Buckley, M. R., Hochwarter, W. A., \& Witt, L. A. (1999, August). Development and initial validation of the political skill inventory. In Academy of Management, 59th annual national meeting, Chicago (pp. 6-11).

Ferris, G., Davidson, S., \& Perrewe, P. (2005). Developing political skill at work. Training-New York then Minneapolis then New York, 42(11), 40. relationship leader-member o work colleagues (Holzbach, 1978).

Ferris, G. R., Gavin, M. B., Perrewe, P. L., Hall, A. T., and Frink, D. D. (2007). Political skill as neutralizer of felt accountability-Job tension effects on job performance ratings: A longitudinal investigation. Organizational Behavior and Human Decision Processes, 102, 226-239.

Ferris, G. R., Perrewé, P. L., Anthony, W. P., \& Gilmore, D. C. (2003). Political skill at work. Organizational influence processes, 395-407.

Ferris, G. R., Treadway, D. A., Kolodinsky, R. W., Hochwarter, W. A. Kacmar, C. J., Douglas, C. and Frink, D. D. (2005). 'Development and validation of the political skill inventory'. Journal of Management, 31, 12652

Ferris, G. R., Treadway, D. C., Perrewé, P. L., Brouer, R. L., Douglas, C., \& Lux, S. (2007). Political skill in organizations. Journal of management, 33(3), 290-320.

Ferris, G.R., Blickle, G., Schneider, P.B., Kramer, J., Zettler, I., Solga, J., Noethen, D., and Meurs, J.A. (2008). Political skill construct and criterion-related validation: A two-study investigation. Journal of Managerial Psychology, 23, 744-771.

Finney, S. J., \& DiStefano, C. (2006). Non-normal and categorical data in structural equation modeling. Structural equation modeling: $A$ second course, 10(6), 269-314

Grosser, T. J. (2014). The effect of political skill and social network structure on innovation and career success. In Academy of Management Proceed ings (Vol. 2014, No. 1, p. 10650). Briarcliff Manor, NY 10510: Academy of Management.

Hair, J. F., Black, W. C., Babin, B. J., \& Anderson, R. E. (2014). Multivariate data analysis: Harlow. UK: Pearson Education Limited.

Holzbach, R. L. (1978). Rater bias in performance ratings: Superior, self-, and peer ratings. Journal of Applied Psychology, 63(5), 579-588

Janssen, O. (2000). Job demands, perceptions of effort-reward fairness, and innovative work behavior, Journal of Occupational and organizational psychology, 73, 287-302.

Jawahar, I. M., Stone, T. H., and Kisamore, J. L. (2007). Role conflict and burnout: The direct and moderating effects of political skill and perceived organizational support on burnout dimensions. International Journal of Stress Management, 14, 142-159.

Kimura, T. (2015). A review of political skill: Current research trend and directions for future research. International Journal of Management Reviews, 17(3), 312-332.

Kolodinsky, R. W., Hochwarter, W. A., and Ferris, G. R. (2004). Nonlinearity in the relationship between political skill and work outcomes: Convergent evidence from three studies. Journal of Vocational Behavior, 65, 294-308

Liu, Y., Ferris, G.R., Zinko, R., Perrewe, P.L., Weitz, B., and Xu, J. (2007). Dispositional antecedents and outcomes of political skill in organizations: A four-study investigation with convergence. Journal of Vocational Behavior, 71, 146-165.

Luthans, F., Hodgetts, R. M., and Rosenkrantz, S. A. (1988). Real managers. Cambridge, MA: Ballinger.

Lvina, E., Johns, G., Treadway, D.C., Blickle, G., Liu, Y., Liu, J. and Ferris, G.R. (2012). Measure invariance of the Political Skill Inventory (PSI) across five cultures. International Journal of Cross-Cultural Management, 12(2), 171-191. http://doi.org/10.1177/1470595812439870.

Lvina, E., Johns, G., Treadway, D.C., Blickle, G., Liu, Y., Liu, J. and Ferris, G.R. (2012). Measure invariance of the Political Skill Inventory (PSI) across five cultures. International Journal of Cross Cultural Management, 12(2), 171-191.

Mainiero, L.A. (1994). On breaking the glass ceiling: the political seasoning of powerful women executives. Organizational Dynamics, 22, pp. 4-20.

Mintzberg, H. (1983). Power in and around organizations (Vol. 142). Englewood Cliffs, NJ: Prentice-Hall.

Mintzberg, H. (1985). The organization as political arena. Journal of management studies, 22(2), 133-154. 
Momm, T., Blickle, G., \& Liu, Y. (2017). Political skill and emotional cue learning. Personality and Individual Differences, 49(5), 396-401.

Moss, J. A. and Barbuto, Jr, E. (2010). Testing the Relationship Between Interpersonal Political Skills, Altruism, Leadership Success and Effectiveness: A Multilevel Model. Institute of Behavioral and Applied Management, 11.2, 155-174.

Perrewé, P. L., Ferris, G. R., Frink, D. D., \& Anthony, W. P. (2000). Political skill: An antidote for workplace stressors. Academy of Management Perspectives, 14(3), 115-123.

Perrewé, P. L., Zellars, K. L., Ferris, G. R., Rossi, A. M., Kacmar, C. J., \& Ralston, D. A. (2004). Neutralizing job stressors: Political skill as an antidote to the dysfunctional consequences of role conflict. Academy of Management Journal, 47(1), 141-152.

Pfeffer, J. (1991). Organization theory and structural perspectives on management. Journal of Management, 17(4), 789-803.

Phipps, S. T., \& Prieto, L. C. (2015). Women versus men in entrepreneurship: A comparison of the sexes on creativity, political skill, and entrepreneurial intentions. Academy of Entrepreneurship Journal, 21(1), 32

Putnick, D. L., \& Bornstein, M. H. (2016). Measurement invariance conventions and reporting: The state of the art and future directions for psychological research. Developmental review, 41, 71-90.
Shaughnessy, B. A., Treadway, D. C., Breland, J. A., Williams, L. V., \& Brouer, R. L. (2011). Influence and promotability: The importance of female political skill. Journal of Managerial Psychology, 26(7), 584-603.

Stone, P. M. (2018). How Have Female African American Chief Diversity Officers (CDO) Made Meaning of the Role Political Skill Plays at Predominately White Research Institutions? (Doctoral dissertation, The George Washington University).

Treadway, D., Campion, E. and Williams, L. (2017), "Sensitivity and Adaptability in the Face of Powerlessness: The Roles of Political Will and Political Skill within the Experience of Powerlessness and its Impact on Stress-Related Outcomes", Power, Politics, and Political Skill in Job Stress (Research in Occupational Stress and Well Being, Vol. 15), Emerald Publishing Limited, pp. 81-103.

Zellars, K. L., Perrewé, P. L., Rossi, A. M., Tepper, B. J., \& Ferris, G. R. (2008). Moderating effects of political skill, perceived control, and job-related self-efficacy on the relationship between negative affectivity and physiological strain. Journal of Organizational Behavior: The International Journal of Industrial, Occupational and Organizational Psychology and Behavior, 29(5), 549-571. 